\section{Receptor activator of nuclear factor kappa B ligand}

\author{
H.-D. Haubeck \\ Wasserburg, Deutschland
}

\section{Synonym(e) RANK(L)}

Definition RANKL ist an der Regulation der Osteoklastenaktivität und damit der Knochenresorption beteiligt.

Beschreibung Die Regulation der Knochendichte erfolgt durch die abgestimmte Aktivität von Osteoblasten und Osteoklasten. Für die Interaktion von Osteoblasten und Osteoklasten ist das RANKL/Osteoprotegerin-System (s. > Osteoprotegerin) von entscheidender Bedeutung. RANKL wird von Osteoblasten sezerniert und bindet an seinen spezifischen Rezeptor RANK auf Osteoklasten. Hierdurch werden die Osteoklasten aktiviert, und es kommt zur Knochenresorption. Die Bedeutung des RANK/RANKL-Systems ergibt sich auch aus dem $>$ Phänotyp der RANKL-defizienten (Knock-out-) Maus. Diese Tiere zeigen neben immunologischen Störungen, die mit einer Expression von RANKL durch aktivierte - T-Lymphozyten erklärt wird, eine ausgeprägte Osteopetrosis. Auch die Wirkung des $>$ Parathormons auf die Osteoklasten erfolgt über das RANK/RANKL-System. Sinkt die - Calciumkonzentration im Serum, wird von der Nebenschilddrüse vermehrt Parathormon sezerniert. Parathormon wirkt aber nicht auf die Osteoklasten, die keinen Parathormonrezeptor besitzen, sondern auf die Osteoblasten, die daraufhin RANKL sezernieren. RANKL bindet dann an seinen Rezeptor RANK auf Osteoklasten und osteoklastären Vorläuferzellen. Die erhöhte Knochenresorption durch die aktivierten Osteoklasten führt zum Anstieg der Calciumkonzentration im Serum. Die Synthese von RANKL durch Osteoblasten wird durch Zytokine, z. B. IL-1 $\beta$, IL-6, IL-11, IL-17 Interleukine und TNF- $\alpha$, > Tumornekrosefaktor- $\alpha$, stimuliert, gleichzeitig erfolgt eine Hemmung der Osteoprotegerinsynthese. Umgekehrt hemmt z. B. IFN- $\gamma$ die Synthese von RANKL und stimuliert die Synthese von Osteoprotegerin. Störungen des Osteoprotegerin/RANKLSystems können einerseits zu osteopenischen Erkrankungen wie der Osteoporose und andererseits zur Osteosklerose führen. Dementsprechend korrelieren die Serumkonzentrationen von RANKL und Osteoprotegerin positiv bzw. negativ mit dem Frakturrisiko. Darüber hinaus könnten die Knochenerosionen bei der rheumatoiden Arthritis u. a. durch eine Aktivierung des RANK/RANKL-Systems durch aktivierte T-Lymphozyten im Gelenk bedingt sein.

Für die Bestimmung der RANKL-Serumkonzentration stehen Enzymimmunoassays zur Verfügung.

\section{Literatur}

Boyle WJ, Simonet WS, Lacey DL (2003) Osteoclast differentiation and activation. Nature 423:337-342 